than their quota and it is hoped that the remaining countries will also make an adequate response to the financial appeal which the Committee has been obliged to make.

The completion and issue of the "Book of the Congress of Zurich in 1931" was reported, and the desirability of securing the further sale of this volume was emphasised. It is believed that the nature and value of this publication have not yet become fully known to many of those who might be interested in it, so that a much larger sale should be attained; this is highly desirable if the future work of the International Association is to go forward vigorously.

The main question dealt with by the Permanent Committee at the Florence meeting was the plan of work to be undertaken at, and in preparation for, the congress which is to be held in London in 1935. It was decided in general terms that the work of the congress should again be organised on lines similar to those which had proved particularly successful at Zurich. The work of the congress will therefore be carried out in four sections or groups, namely : A, Metals (president, Prof. C. Benedicks, Sweden); B, Inorganic Materials, including stone, cement, concrete, etc. (president, Prof. E. Suenson, Copenhagen) ; C, Organic Materials (president, Dr. F. Barta, Prague); and D, Questions of general importance. For Group D the late Dr. Burgess of Washington had been appointed president. His untimely death unfortunately renders it necessary to appoint a new president for this Group, but the appointment has not yet been made as it was thought desirable to await suggestions from various countries. In each of these Groups only a limited number of subjects will be discussed, the whole of one session being devoted, as was done at Zurich, to the discussion of a single question or group of questions. The selection of subjects with which it is proposed to deal has been provisionally made as follows :

Group A : Corrosion, light alloys, welding, progress of metallography, behaviour under machining and abrasion.

Group B: concrete and ferro-concrete, testing methods for ceramic materials, weathering of natural and artificial stone.
Group C: textiles (artificial silks), wood cellulose, india-rubber (cautchouc), preservation of timber.

Group D: progress in testing machines and measuring appliances, materials of construction in the laboratory and in service, methods and concepts of physics and chemistry in their application to problems of testing materials, sound and heat trans. mission of materials.

While it has been thought desirable to lay down in these general terms the subjects to be discussed at the congress in London, it is realised that in the intervening period developments may occur which may make an alteration of this programme desirable.

In view of the financial stringency which the International Association feels, in common with the industrial and technical world upon which it depends for support, it may not be possible to issue any intermediate publications such as those issued some eighteen months before the congress at Zurich. None the less, the work of the Association will be carried forward actively, mainly through the presidents of the four Groups and also by a number of international committees which have been appointed. The latter will carry on their work almost entirely by correspondence, but meetings in connexion with them will take place at or immediately prior to the congress in London in 1935.

In spite of exceedingly difficult circumstances, it will be seen that the International Association for Testing Materials is carrying on its work in an active and energetic manner, and an appeal is made for support in all countries both from societies, institutions and industrial firms, and also from all those individuals who are in one way or another concerned with the problems of testing.

The secretariat of the International Association is at Zurich (Leonhardstrasse 27) and Prof. M. Ros̆, head of the Swiss Federal Testing Laboratory, has consented to retain the office of general secretary until the congress in London. The British headquarters of the association are in the hands of $\mathbf{M r}$. G. C. Lloyd (honorary secretary and treasurer) at the offices of the Iron and Steel Institute, 28 Victoria Street, London, S.W.1.

\title{
Air Waves from Experimental Explosions
}

\begin{abstract}
$\mathrm{T}$ HAT the audibility of explosions must be due in some way to conditions in the upper air at considerable heights above the ground has long been recognised. It is therefore appropriate that experimental explosions should be included in the programme of intensive theteorological research during the Polar Year. The first experiments to be organised in accordance with this programme by Prof. $H$. Hergesell, president of the International Commission for the Investigation of the Upper Air, took place on December 15. These explosions were at Russian Harbour in Novaya Zemlya and at Oldebroek in Holland. At each place there were to be four explosions, at 6.0, 6.6, 7.0 and 7.6 G.M.T. Four Kühl undographs were to be operated in the neighbourhood of the Russian Harbour explosions, three in Novaya Zemlya and one in Franz Josef Land. Several undographs were to be used in Germany and one, at Flushing, in Holland. For co-operation by Great Britain, the sound-ranging apparatus which is in regular use for recording at Birmingham, Bristol,
\end{abstract}

Cardiff and Nottingham the air waves caused by firing at Woolwich, was available, as well as similar apparatus at Foulness near the mouth of the Thames and at Hythe near Folkestone.

According to newspaper reports, the explosions at Oldebroek were not heard over any large area. The air waves were recorded at Potsdam and at Lindenberg. It is surmised that the photographic records from the other stations in Germany would be sent to a central point to be developed, so that some delay in the announcement of results is to be anticipated.

There was no reception of the air waves at Foulness, Hythe or Nottingham. Definite information is not yet available from Birmingham and Bristol. At the Cardiff station, Cefn Mably, Dr. J. Shaxby obtained a series of records showing disturbances, mostly minute, which were at first thought to indicate the reception of waves from the explosions at Oldebroek, but this interpretation is very doubtful.

Of the reports which have reached the Superintendent of Kew Observatory, in response to a

No. 3296, Vol. 130] 
notice issued to the Press by the Air Ministry, one of the most valuable is from Miss Mabel Williams, who noticed at Cambridge that the window of her room vibrated vigorously at $6.21 \frac{1}{2}$, at $6.26 \frac{1}{2}$ and again at 7.261. Sir John and Lady Smith, who were listening at Havering-atte-Bower in Essex, report that, between 19 and 22 minutes after 7 , hundreds of birds in the trees surrounding their house suddenly made startled cries as if in danger. A considerable number of people in various parts of England have reported that they heard noises, which they attributed to the experimental explosions, but there was no area in which the sounds attracted general attention, and observers who listened with the intention of timing the series were not successful.

It is in accordance with previous experience that the infra-sonic waves, which carry most of the energy of an explosion, can be effective at great distances, at places where no sound can be perceived by ear. In the present case, the infra-sonic waves seem to have passed over Foulness to make the twigs quiver in the trees at Havering-atte-Bower and to shake the window at Cambridge. The distance from Oldebroek to Cambridge is $400 \mathrm{~km}$.

\section{University and Educational Intelligence}

LoNDoN.-The title of reader in petrology in the University of London has been conferred on Dr. Alfred Brammall in respect of the post held by him at the Imperial College-Royal College of Science.

THE problem of the deaf, especially of their education, training and employment, is dealt with exhaustively in a report by Dr. A. Eichholz (London, H.M. Stationery Office, pp. 206, 3s.). The report is based on an investigation begun in April 1930, with the object of clearing up the facts upon which various representations have been made from time to time since 1924 (when the National Institute for the Deaf was founded) to Parliament and to the Ministry of Health and the Board of Education. Comprehensive statistics of the incidence of deafness in adult life are lacking, but indications that deafness of a disabling character exists in a marked degree among the general population are afforded by rejections for ear-diseases of applicants for service in the Army ( 5 per cent) and Royal Air Force ( 2 per cent). Among children, some gratifying decreases, attributable to arrangements by local education authorities for inspection and treatment, are reported. The statistics of deaf and dumb children also show a gradual decrease, attributable to improvement in the general health supervision of the population, from 4,173 in 1924 to 3,621 in 1930 . The report suggests, inter alia, that arrangements for the detection of defects of hearing should be improved by the use of acoumetric apparatus such as the audiometer now used in many American cities, that the Ministry of Health and Medical Research Council should institute a study of the age incidence, causes and treatment of ear defect, that provision for vocational courses for deaf people should be made in the north, west and midland districts of England and in South Wales, and that a secondary school for the deaf should be provided.

THe International Federation of University Women (Crosby Hall, Cheyne Walk, S.W.3) has published a full report of its sixth conference, held last August at Edinburgh. Created, mainly on American and British initiative, in the year following the War as a means of promoting international understanding and friendship, this organisation has year by year extended its membership until it now comprises, in addition to those of the United States and the British Empire, associations of university women of every country of Europe (outside Russia), and Egypt, Palestine, Mexico and Brazil. The list of participants in the conference reaches the imposing total of 575 and although the American and British largely predominated, thirty countries in all were represented. Among the subjects dealt with were: international aspects of the development of science, co-ordination of university standards, the contribution of women to the newer knowledge of nutrition, epidemics of plant diseases and, in one of the sectional meetings, the careers open to women biologists. At this sectional meeting there was a consensus of opinion that it is far more difficult for women than for men to obtain work as biologists, that this is not due to their unsuitability for any of the kinds of work available (with the possible exception of certain kinds of tropical field work) and that there is consequently a waste of women biologists. Two members undertook to investigate this matter. Statistics of membership of the affiliated associations show that seventy per cent of the aggregate total are American university women. These constitute the financial backbone of the Federation. The German membership decreased heavily in 1932, while the Austrian increased by seventy-six per cent.

Eddcation in Belgium is described by Dr. J. F. Abel, of the United States Office of Education, in a pamphlet of 145 pages prepared after investigation on the spot last year and now published by the Government Printing Office, Washington. One of the most striking facts to which Dr. Abel directs attention is the very heavy enrolment in the kindergartens -nearly a quarter of a million; this being nearly as large a proportion of the total number of children of kindergarten age as the proportion of the enrolment in primary schools to the number of children of primary school age. The secondary school curricula in Belgium have lately been remodelled so as to lessen school work and give more opportunity for recreation and physical development, the number of school hours being limited to 34 a week and teachers being warned that assigning tasks for home study is generally useless, and that it is habit rather than subject matter that the pupil is to acquire. Physical and biological sciences figure in the curricula of all divisions of secondary schools, but the time allotted is in general only two hours a week. Commenting on the problems arising out of bilingualism, Dr. Abel observes that the Belgians have proved that language unity is not necessary to, or perhaps advantageous for, national unity where appropriate arrangements are made in the schools. In the attempt to give effect to the principle of equal instruction for equal intelli. gence, very elaborate procedures have been prescribed for the guidance of the committees entrusted with the task of selecting children in primary schools for bursaries; the model school card enumerates fortyone characteristics to be estimated in the case of each pupil. An interesting account is given of the Colonial University, which selects annually twenty young men who contract to serve at least three years in the Congo after a four years' course.

No. 3296, Vol. 130] 